\title{
Ensayo crítico sobre las posibles estrategias adoptadas para hacer frente al cierre de escuelas causado por COVID-19: Red Municipal de Educación de Campinas (SP) - Brasil
}

\section{Critical essay on the possible strategies adopted to face the closure of schools caused by COVID-19: Municipal Education Network of Campinas (SP) - Brazil}

Vitorino, Artur José Renda ${ }^{1}$ PPGE - PUC Campinas (SP) - Brasil arturvitorino@puc-campinas.edu.br https://orcid.org/0000-0002-8654-3182

\author{
Mello, Juliano Pereira de ${ }^{2}$ \\ PPGE -PUC Campinas (SP) - Brasil \\ juliano.mello@puccampicas.edu.br \\ https://orcid.org/0000-0002-6780-5685
}

Resumen: Pelo aporte teórico sobre a finalidade da educação proposta por Biesta (2012), dos possíveis percalços causados pelo chamado "abstracionismo pedagógico" apresentado por Azanha (1992) e das considerações sobre o conceito de "semdomicílio" utilizado por Popkewitz e Lindblad (2016), foi interpretado o arcabouço legal normativo da educação básica brasileira em relação ao ensino a distância e à educação à distância e dos dilemas verificados no âmbito do Sistema Municipal de Ensino de Campinas (SP) em tempos de Pandemia Covid-19. Assim, a partir de uma breve exposição da rede municipal de educação infantil na cidade de Campinas, Estado de São Paulo, no Brasil, a apresentação fará uma análise sobre as notas elaboradas pela organização da sociedade civil Todos pela Educação (2020): "Ensino a distância na educação básica frente à pandemia da COVID-19" e "Políticas Educacionais na Pandemia da COVID-19: O que o Brasil pode aprender com o resto do mundo?" do Banco Mundial (2020), cuja finalidade é demonstrar, no recorte espacial delimitado, que em tais documentos as possíveis estratégias adotadas para enfrentamento ao fechamento das escolas provocadas pela COVID-19 são ambíguas, pois há um distanciamento conceitual considerável entre o ensino a distância e as estratégias propostas para o período de impedimento das atividades letivas nas escolas básicas.

Palabras clave: COVID-19; Ações da gestão municipal de Campinas; Banco Mundial; Escolas da Educação Básica; Campinas (SP-Brasil)

Abstract: Due to the theoretical contribution on the purpose of education proposed by Biesta (2012), the possible obstacles caused by the so-called "pedagogical abstractionism" presented by Azanha (1992) and the considerations on the concept of "homelessness" used by Popkewitz and Lindblad (2016), the normative legal framework of Brazilian basic education was interpreted in relation to distance education and distance education and the dilemmas verified within the scope of the Municipal Teaching System of Campinas (SP) in times of Pandemia Covid-19. Thus, based on a

Ensaio crítico sobre as possíveis estratégias adotadas para o enfrentamento ao fechamento das escolas provocado pela COVID-19: rede municipal de educação básica de Campinas (SP) - 
Congreso Internacional de Gestión Educativa, 06 y 07 de noviembre de 2020.

Pontificia Universidad Católica del Perú

brief presentation by the municipal network of early childhood education in the city of Campinas, State of São Paulo, Brazil, the presentation will analyze the notes prepared by the civil society organization Todos pela Educação (2020): "Teaching the distance in basic education in face of the COVID-19 pandemic "and" COVID-19 Pandemic Education Policies: What can Brazil learn from the rest of the world? "World Bank (2020), whose purpose is to demonstrate, in the delimited space, that in such documents the possible strategies adopted to face the closing of schools caused by COVID-19 are ambiguous, as there is a considerable conceptual distance between distance learning and the strategies proposed for the period of impediment of teaching activities in basic schools.

Keywords: COVID-19; Campinas municipal management actions; World Bank; Basic Education Schools; Campinas (SP-Brazil)

\section{Introdução}

Tendo em vista as discussões sobre a finalidade da educação a partir de Biesta (2012), que nos coloca o desafio para definirmos uma "boa educação", a qual, nas últimas décadas, está quase que totalmente reduzida à mensuração e à comparação de resultados educacionais entre Países, Estados e Municípios, os quais, no atual contexto de pandemia, tendem a ter suas desigualdades educacionais cada vez mais reveladas e ampliadas a partir, principalmente, da manutenção dos critérios que têm servido para caracterizar e medir a chamada "educação de qualidade".

Também ressaltamos os cuidados para evitarnos a armadilha que Azanha (1992) denominou de "abstracionismo pedagógico", o qual se caracteriza pela leviandade de descrever, explicar ou compreender situações educacionais reais, desconsiderando as determinações específicas de sua concretude, para ater-se apenas a "princípios" ou "leis" gerais que, nas suas abrangências abstratas são, aparentemente, suficientes para dar conta das situações analisadas, porém, acabam sendo evidenciadas em suas limitações, principalmente, agravadas quando nos deparamos com as situações de exceção impostas em um contexto de calamidade pública, ou mesmo, de isolamento social permeado por uma grande diversidade de situações encontradas em cada sistema de ensino e, principalmente, em cada escola e sua comunidade formada por profissionais, alunos(as) e famílias.

Consideramos também o conceito de "sem-domicílio" utilizado por Popkewitz e Lindblad (2016, p.739), os quais esclarecem que essa ideia envolve abstrações sobre a existência de uma distinção humana, que parece não ter um lugar histórico, uma especificidade cultural e limites geográficos, ou seja, trata-se de uma abstração que propõe e/ou pressupõe um aluno universal, um professor universal, uma escola universal e, consequentemente, um cidadão universal, como que genérico e estereotipado - que remete à um padrão de educação e ensino universal.

Então, ainda ressaltando esse tempo da busca por soluções que respondam aos impactos da Pandemia Covid-19 na educação mundial e, aqui, mais especificamente, tratando das ações na escala do sistema municipal de ensino de Campinas (SP), propomos uma

Ensaio crítico sobre as possíveis estratégias adotadas para o enfrentamento ao fechamento das escolas provocado pela COVID-19: rede municipal de educação básica de Campinas (SP) -

Brasil - Vitorino, Artur \& Mello, Juliano.

DOI: https://doi.org/10.18800/cige2020.007 
Congreso Internacional de Gestión Educativa, 06 y 07 de noviembre de 2020.

Pontificia Universidad Católica del Perú

análise nos comprometendo com o que Biesta (2012, p.813-814) chama de valores últimos da educação, ou seja, valores acerca de objetivos e propósitos da educação, para além de uma educação tida como eficaz por atender, muitas vezes, de forma consensualmente imposta, muito mais aos interesses de alguns grupos hegemônicos em detrimento de outros que são diretamente afetados pelas decisões, porém anulados em suas possibilidades de construírem outras propostas e práticas que atendam as diferentes realidades escolares.

\section{As notas emitidas pelo Banco Mundial e Todos pela Educação (TPE)}

Na nota do Banco Mundial (2020): "Políticas Educacionais na Pandemia da COVID-19: O que o Brasil pode aprender com o resto do mundo?", são apresentadas experiências internacionais para mitigar os efeitos da pandemia da COVID-19 na educação, as quais seriam exemplos exitosos para as ações a serem adotadas pelos sistemas de ensino brasileiros: Federal, Estaduais e Municipais.

Ressaltamos que o Banco Mundial (2020), ao indicar o que as "redes de educação" podem fazer para promover aprendizagem e tempo pedagógico de forma equitativa, mesmo com as escolas fechadas, utiliza, indistintamente os seguintes termos: "educação a distância", "ensino a distância", aprendizagem a distância", "aulas a distância" e "ensino EaD", os quais, associa às atividades e ferramentas, que dependem das condições de conectividade, principalmente, por meio de acesso a internet (BANCO MUNDIAL, 2020, p.2).

Além disso, o Banco Mundial (2020) apresenta dados que revelam a grande desigualdade socioespacial brasileira (por região político-administrativa e na comparação entre os espaços urbano e rural) com relação ao apoio das famílias ao estudo das crianças em casa, conforme dados do SAEB (2017), do uso da internet em sala de aula, conforme Censo Escolar (2019) e da presença de computadores, tablets e celulares nos domicílios brasileiros, conforme PNAD contínua (2017).

Porém, o Banco Mundial (2020), mesmo frente aos dados supracitados e sem apresentar informações sobre as efetivas condições de acesso domiciliar à internet no Brasil, ao indicar o que as experiências internacionais dizem da implementação de educação a distância em um cenário denominado de "baixa capacidade" (BANCO MUNDIAL, 2020, p.3), ainda ressalta a importância da avaliação da infraestrutura e capacidade dos estudantes e professores de se adaptarem às tecnologias de ensino a distância, o qual, está totalmente voltado às ações que considerem “... distintos caminhos de ensino a distância com aulas virtuais por meio da internet, além da distribuição de materiais impressos para os alunos". (BANCO MUNDIAL, 2020, p.03)

Por fim, destacamos abaixo um trecho em que o Banco Mundial (2020, p.3), fazendo uso da expressão "ensino EaD", justifica com três argumentos as dificuldades de uma suposta transição internacional para o ensino a distância:

(i) à falta de familiaridade com as ferramentas utilizadas no ensino $\mathrm{EaD}$, (ii) à falta de um ambiente familiar motivador ao aprendizado online bem-sucedido, (iii) e à falta de congruência entre o que antes era ensinado em sala de aula e o que passa a ser ensinado online.

Ensaio crítico sobre as possíveis estratégias adotadas para o enfrentamento ao fechamento das escolas provocado pela COVID-19: rede municipal de educação básica de Campinas (SP) -

Brasil - Vitorino, Artur \& Mello, Juliano.

DOI: https://doi.org/10.18800/cige2020.007 
Congreso Internacional de Gestión Educativa, 06 y 07 de noviembre de 2020.

Pontificia Universidad Católica del Perú

Em seguida, considerando a nota técnica "Ensino a distância: Educação Básica frente à pandemia da Covid-19" da Organização da Sociedade Civil Todos pela educação (TPE, 2020), a mesma começa ressaltando ser a primeira versão (abril de 2020) e reconhecendo que é um documento em construção tendo em vista as novas discussões e contribuições advindas das experiências nacionais e internacionais, bem como esclarecendo que a bibliografia educacional disponível está com a maior parte de seus estudos proveniente de tempos de normalidade, e não excepcionais como agora, ao passo que nenhuma solução é, em um contexto como o atual, perfeita e definitiva. (TPE, 2020, p.02)

Conforme dados da UNESCO (2020 apud TPE, 2020, p.03), as medidas de distanciamento social no atual contexto de Pandemia Covid-19, na Educação, de maneira geral, levaram ao fechamento de escolas públicas e particulares, com interrupção de aulas presenciais. Sendo que, $91 \%$ do total de alunos do mundo e, mais de $95 \%$ da América Latina estão, temporariamente, "fora da escola" devido à Covid-19.

Além disso, a nota apresenta dados (abril de 2020) revelando que as redes estaduais, são aquelas que mais têm avançado em transferir aulas e outras atividades pedagógicas para formatos a distância, por meio, principalmente, da disponibilização de plataformas online, aulas ao vivo em redes sociais e envio de materiais digitais aos alunos.

Segundo o TPE (2020), a nota buscou evitar o que chamaram de "leitura fria" das pesquisas sobre ensino a distância, as quais, em geral, se concentram em comparar "aulas a distância" com "aulas presenciais", pois no contexto atual, a questão é, fundamentalmente, uma discussão entre "aulas a distância" e a "não realização de aulas", o que, inclusive, para melhor elucidarem seu posicionamento frente a esse dilema, apontam similaridade com experiências de países que interromperam $o$ funcionamento de escolas por longos períodos devido a situações de guerra, crises de refugiados, desastres naturais e epidemias, nas quais, segundo a referida nota, a escolha do poder público em nada fazer, sob o argumento de que não é possível chegar em todos, tende a aumentar as desigualdades resultantes da situação de emergência.

A nota do TPE (2020, p.04) revela que a maioria das chamadas redes estaduais está utilizando como estratégia de ensino a distância, principalmente, as plataformas online, ao passo que, as chamadas redes municipais, em sua maioria, não estão oferecendo nenhuma opção das onze estratégias pesquisadas.

O recorte da pesquisa e análise apresentada pela nota do TPE (2020) em relação ao ensino fundamental e ensino médio, segundo esse mesmo documento, exclui a primeira etapa da Educação Básica - a Educação Infantil (Creche e Pré-Escola) - devido ao entendimento de que a dinâmica educacional para crianças de 0 a 5 anos difere demasiadamente das dinâmicas nas etapas subsequentes. Assim, merecendo uma abordagem e análise específicas quanto à pertinência de atividades a distância em situações de fechamento provisório de escolas.

A nota do TPE (2020, p.05) aponta quatro mensagens que objetivam, prioritariamente, qualificar o debate público educacional, a saber: a) as soluções de ensino remoto podem contribuir e devem ser implementadas, porém, desde já, com a devida atenção ao planejamento de volta às aulas; b) uma estratégia consistente para o ensino remoto é aquela que busca mitigar as condições heterogêneas de acesso e os diferentes efeitos de

Ensaio crítico sobre as possíveis estratégias adotadas para o enfrentamento ao fechamento das escolas provocado pela COVID-19: rede municipal de educação básica de Campinas (SP) -

Brasil - Vitorino, Artur \& Mello, Juliano.

DOI: https://doi.org/10.18800/cige2020.007 
Congreso Internacional de Gestión Educativa, 06 y 07 de noviembre de 2020.

Pontificia Universidad Católica del Perú

soluções a distância em função do desempenho prévio dos estudantes; c) Ensino remoto não é sinônimo de aula online, ou seja, há diferentes maneiras de estimular a aprendizagem a distância e, se bem estruturadas, atividades educacionais podem cumprir mais do que uma função puramente acadêmica; d) Mesmo a distância, atuação dos professores é central.

\subsection{Uma breve análise das notas}

Ao compararmos a utilização dos dados sobre as características de escolas, estudantes, professores e famílias brasileiras com relação ao acesso à internet, acesso a equipamentos de tecnologia da informação (TICs), de apoio familiar para o estudo em casa, de formação para trabalho com tecnologias educacionais para os professores e de escolas com equipamentos e uso de internet, ressaltamos que a nota do TPE (2020), embora apresente menos dados do que a nota do Banco Mundial (2020), acaba por considerar os dados apresentados com proposições que indicam a necessidade de se respeitar e atender de forma diversa as especificidades de cada lugar frente a grande desigualdade socioespacial brasileira, ou seja, segundo Popkewitz e Lindblad (2016, p.729-730), a crítica que pode ser feita às estatísticas educacionais não é em serem essencialmente "boas/más", sobre sua utilidade, ou viés; nem é para censurar ou condenar números ou estatísticas utilizadas na educação, mas, sobretudo, deve ser para colocar as propostas e ações em um contexto cultural, político (e espacial) mais amplo.

A nota do Banco Mundial (2020, p.02-03) cita três vezes que a educação brasileira passa por uma "transição repentina para ensino a distância" e que essa suposta transição, segundo evidências internacionais, teria um efeito negativo devido a aspectos relacionados à falta de familiaridade de professores e estudantes com as ferramentas utilizadas no ensino $\mathrm{EaD}$, à falta de um ambiente familiar motivador ao aprendizado online bem-sucedido e à falta de congruência entre o que antes era ensinado em sala de aula e o que passa a ser ensinado online, de acordo com Popkewitz e Lindblad (2016, p.728), ressaltamos que tais afirmações colocam as populações vistas meramente como dados para identificar um campo de intervenção e planejamento social, a fim de trazer uma suposta melhoria social e progresso totalmente descontextualizada.

Sendo assim, as afirmações do Banco Mundial (2020) supracitadas, desconsideram totalmente uma abordagem diagnóstica e histórica em que:

\footnotetext{
“... questionar como, historicamente, os números tornam-se plausíveis e são considerados 'razoáveis', como uma maneira de pensar sobre política e investigação, e questionar sobre os limites de tal pensamento em questões sobre a inclusão e exclusão social”. (Popkewitz e Lindblad, 2016, p.729)
}

Ressaltamos que os conceitos de "educação a distância", "ensino a distância" e "ensino remoto" são tratados, em certa medida, com mais cuidado na nota do TPE (2020), enquanto na nota do Banco Mundial (2020), os conceitos de "educação a distância", "ensino a distância", aprendizagem a distância", "aulas a distância" e "ensino EaD" são utilizados de maneira indiscriminada, sendo assim, além de demonstrar uma aparente

Ensaio crítico sobre as possíveis estratégias adotadas para o enfrentamento ao fechamento das escolas provocado pela COVID-19: rede municipal de educação básica de Campinas (SP) -

Brasil - Vitorino, Artur \& Mello, Juliano.

DOI: https://doi.org/10.18800/cige2020.007 
Congreso Internacional de Gestión Educativa, 06 y 07 de noviembre de 2020.

Pontificia Universidad Católica del Perú

falta de rigor conceitual na forma de apresentar as análises e propostas, bem como suas consequências, conforme a complexidade do tema, também remete-nos ao que Azanha (1992) chamou de "abstracionismo pedagógico", ou seja, a:

“...veleidade (leviandade) de descrever, explicar ou compreender situações educacionais reais, desconsiderando as determinações específicas de sua concretude, para ater-se apenas a 'princípios' ou 'leis' gerais que na sua abrangência abstrata seriam, aparentemente, suficientes para dar conta das situações focalizadas.” (AZANHA, 1992, p.42)

Sendo assim, podemos dizer que, além de encontrarmos marcas desse estilo de investigação educacional caracterizado como "abstracionismo pedagógico" (AZANHA, 1992, p.42) na nota do Banco Mundial (2020), pois não conseguiram, de fato, mais do que utilizarem-se da teoria disponível para tentarem efetuar operações formais de classificação de "fatos" da realidade, ou seja, como se essas operações constituíssem explicações em si mesmas, consequentemente, resumindo a compreensão histórica na (mera) "aplicação" de "referenciais" a uma realidade, a qual, inclusive, parece ser negligenciada pelo documento, bem como, muito mal elaborada na maneira de uso dos conceitos.

Segundo Azanha (1992, p.43), muitas vezes, o "abstracionismo pedagógico" é apenas uma forma ingênua de encaminhamento do exame de um assunto, no qual o estudo da realidade é substituído por um jogo verbal semanticamente vazio, porém, outras vezes, o abstracionismo mais parece ser um claro golpe de astúcia, ideológica ou não.

Então, dado o atual contexto de total exceção na educação mundial e brasileira causado pela Pandemia Covid-19, mais do que nunca, ressaltamos, assim como Azanha (1992, p.45), a necessidade das pesquisas sobre a educação brasileira e suas consequentes análises, fundamentarem-se em cuidadosos e preliminares estudos descritivos, com uma abordagem histórica da instituição escolar e, assim, sermos capazes de captar as efetivas transformações que ocorreram nas últimas décadas e, de forma repentina nos últimos meses, as necessidades adaptativas momentâneas que estão ocorrendo nesse momento excepcional.

Sendo assim, Azanha (1992, p.47) também nos adverte que:

\footnotetext{
“... o fato de que essa espécie de discurso abstrato sobre educação tem um efeito paralisante sobre a própria ação educativa. Pois, negando-se qualquer grau de autonomia às práticas escolares concretas e considerando-as invariavelmente como mero resíduo de forças exteriores a elas, eventuais características que assumam num certo momento só seriam modificáveis por alterações nessas forças e nunca por uma mudança interior nas próprias práticas.” (AZANHA, 1992, p.47)
}

No sentido de considerar os possíveis efeitos paralisantes supracitados em função dos "abstracionismos pedagógicos" que ignoram as diferentes práticas escolares enquanto possibilidades reais de promoção da educação a partir de diferentes estratégias de

Ensaio crítico sobre as possíveis estratégias adotadas para o enfrentamento ao fechamento das escolas provocado pela COVID-19: rede municipal de educação básica de Campinas (SP) -

Brasil - Vitorino, Artur \& Mello, Juliano.

DOI: https://doi.org/10.18800/cige2020.007 
ensino, temos que, embora as notas aqui analisadas não apresentem definições sobre os princípios da educação e seus objetivos, pois mencionam tão somente a manutenção do processo ensino-aprendizagem, a nota do TPE (2020), mapeou 11 estratégias de ensino a distância (digitais e analógicas), ao passo que, a nota do Banco Mundial (2020), mesmo que propondo apresentar exemplos bem sucedidos de ações educacionais no mundo para o Brasil, ateve-se, prioritariamente, às propostas de atividades digitais e dependentes de internet.

\section{Influêcias, Legislação e Normas no Sistema Educacional Nacional}

Procuramos analizar como um sistema educacional nacional, o qual prouramos sintetizar na figura 1 , respondeu aos discursos regulatórios transnacionais, aos think tanks perante a pandemia da Covid-19 até o nível local.

Fig. 1 - Influências, Legislação e Normas - Sistema Nacional de Educação - Brasil

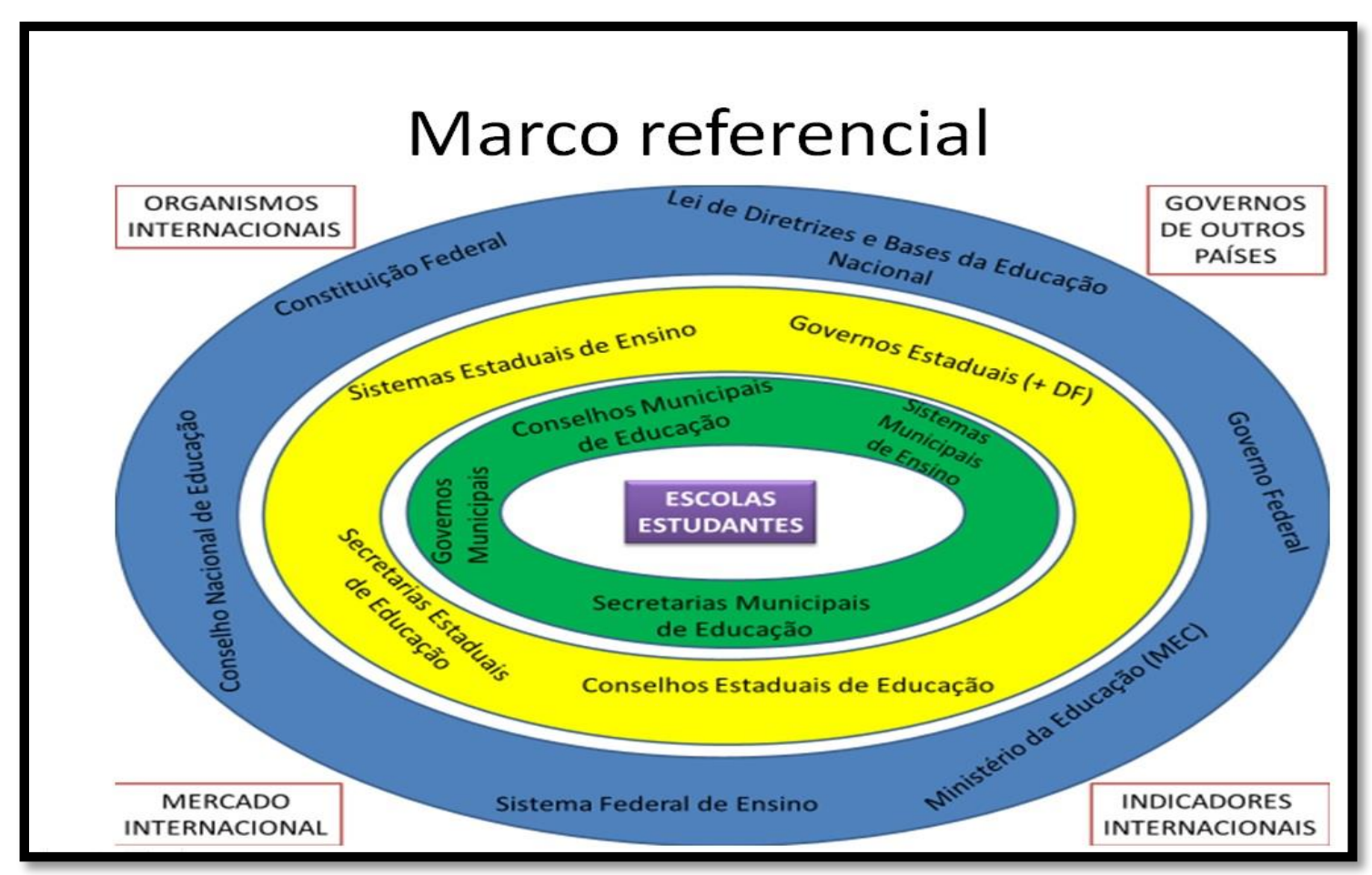

Fonte: Elaborado pelos autores.

Com relação ao ensino a distância, a LDBEN 9394/96 afirma que: "o Ensino Fundamental será presencial, sendo o ensino a distância utilizado como complementação da aprendizagem ou em situações emergenciais". (BRASIL, 1996). No contexto da Pandemia Covid-19 com o fechamento das escolas brasileiras a partir de março de 2020, temos que, no dia de $1^{\circ}$ de abril de 2020, por meio da Medida Provisória n $934 / 2020$, considerando a situação de emergência de saúde pública de que trata a Lei $\mathrm{n}^{\mathrm{o}} 13.979$, de 6 de fevereiro de 2020, o poder executivo federal estabeleceu a

Ensaio crítico sobre as possíveis estratégias adotadas para o enfrentamento ao fechamento das escolas provocado pela COVID-19: rede municipal de educação básica de Campinas (SP) -

Brasil - Vitorino, Artur \& Mello, Juliano.

DOI: https://doi.org/10.18800/cige2020.007 
Congreso Internacional de Gestión Educativa, 06 y 07 de noviembre de 2020.

Pontificia Universidad Católica del Perú

desobrigação do cumprimento dos 200 dias letivos e a manutenção da exigência do cumprimento da carga horária mínima de 800 horas na Educação Básica (educação infantil, ensino fundamental e ensino médio), a qual, independente das adequações necessárias, também tem exigência de manutenção amparada no parágrafo $2^{\circ}$ do Artigo 23 da LDBEN 9394/96.

Em 18/08/2020, foi publicada a Lei 14.040/2020 que estabelece normas educacionais excepcionais a serem adotadas durante o estado de calamidade pública reconhecido pelo Decreto Legislativo ${ }^{\circ}$ 06, de 20 de março de 2020 e altera a Lei 11.947/2020, de 16 de junho de 2009, a qual, em seu inciso I do Art. $2^{\circ}$ continua desobrigando o cumprimento mínimo dos duzentos dias letivos (já anteriormente definido pela MP 934/2020) e acrescenta, também em caráter excepcional, a não obrigatoriedade das 800 horas letivas na Educação Infantil, o que, atende às diversas solicitações contidas no Parecer $\mathrm{CNE} / \mathrm{CP}^{\circ}{ }^{\circ} 05 / 2020$.

Amparado no Parecer do CNE/CP 05/2020, o Conselho Municipal de Educação de Campinas, publicou a Res. CME 01/2020, na qual, dispõe quanto à reorganização dos calendários escolares, no âmbito do Sistema Municipal de Ensino de Campinas e, mais específicamente, no atendimento escolar da Secretaria Municipal de Educação de Campinas (figura 2) devido ao surto global da COVID-19.

Fig. 2 - Secretaria Municipal de Educação de Campinas (SP)

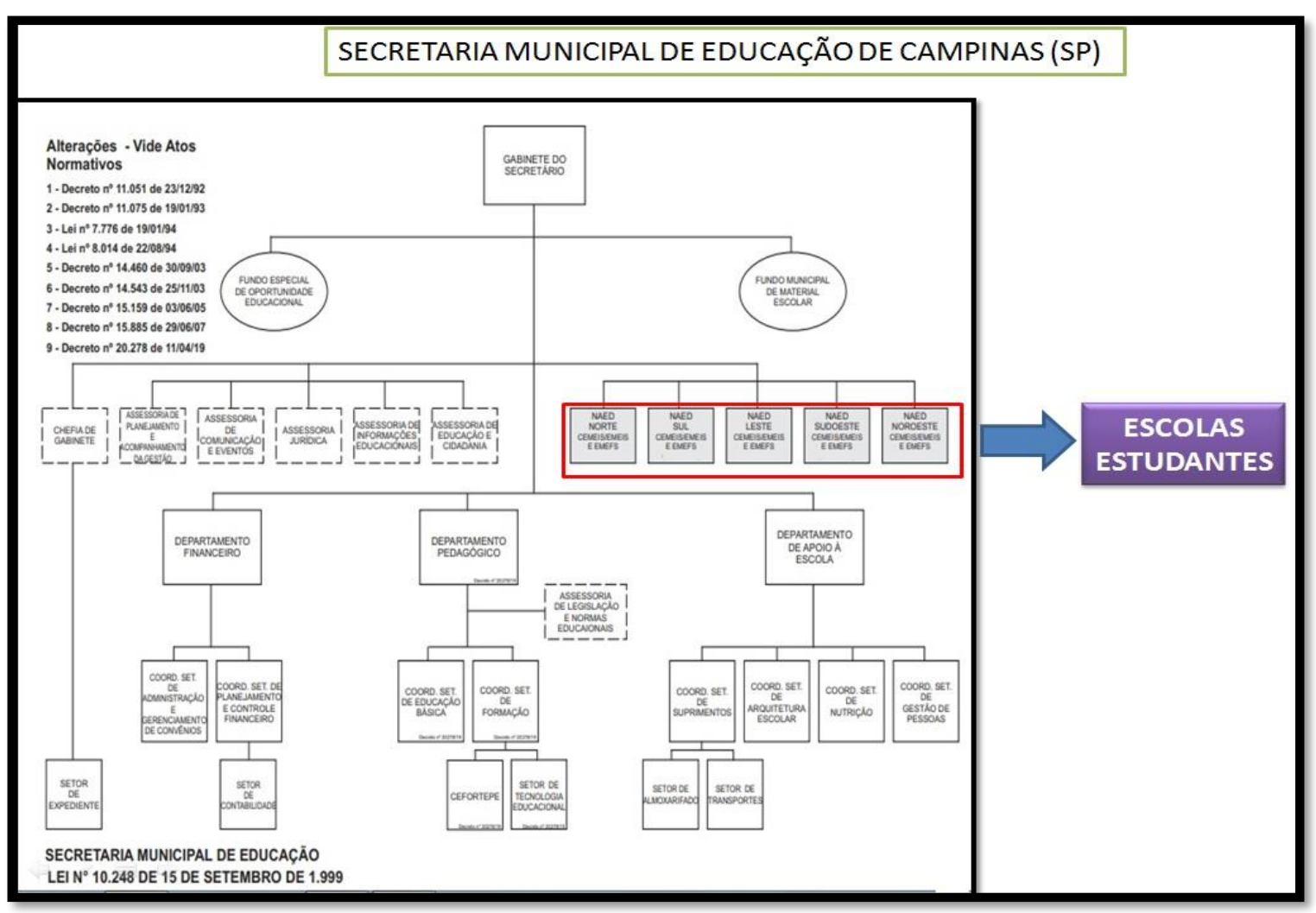

Fonte: Elaborado pelos autores.

Ensaio crítico sobre as possíveis estratégias adotadas para o enfrentamento ao fechamento das escolas provocado pela COVID-19: rede municipal de educação básica de Campinas (SP) -

Brasil - Vitorino, Artur \& Mello, Juliano.

DOI: https://doi.org/10.18800/cige2020.007 
Congreso Internacional de Gestión Educativa, 06 y 07 de noviembre de 2020.

Pontificia Universidad Católica del Perú

Na Res. CME 01/2020, foi indicado computar na carga horária de atividade escolar obrigatória para o ensino fundamental, as atividades programadas fora da escola, no limite máximo de $15 \%$ do total das 800 horas previstas (MP 934/2020), preservada a natureza da relação professor-aluno e garantido o acesso de todos os envolvidos.

\section{Resultados}

Pela teoria geral dos sistemas, de Niklas Luhmann (1984), aliado ao aporte teórico sobre a finalidade da educação proposta por Biesta (2012), dos possíveis percalços causados pelo chamado "abstracionismo pedagógico" apresentado por Azanha (1992), das considerações sobre o conceito de "sem-domicílio" utilizado por Popkewitz e Lindblad (2016), e do arcabouço legal e normativo referente à educação básica na escala federal e municipal foram analisados os estratagemas dos discursos regulatórios transnacionais sobre educação num âmbito local apresentados até aquí chegando às seguintes considerações:

a) Pelo aporte teórico de Luhmann, pode-se afirmar que o sistema educacional brasileiro, em sua instância local (municipal), é um sub-sistema cujos procedimentos específicos, em última instância, não determinam a sua estabilidade e dinâmica. Assim, os componentes que regem as atividades escolares, no Brasil, não apresentam dinâmica e lógica próprias em sua gestão.

b) Tanto a nota do Banco Mundial (2020), como a nota do TPE (2020), elas trouxeram como principal objetivo das ações propostas a preocupação com a aprendizagem dos estudantes. Tal emergência discursiva dessa nova linguagem centrada no conceito de aprendizagem, demonstra-o como um conceito individualista, manifesta-se na redefinição do ensino como facilitação da aprendizagem e da educação como o provimento de oportunidades de aprendizagem ou de experiências de aprendizagem.

c) O resultado da ascensão da aprendizagem em detrimento de uma definição ampla de educação, resultaria em uma combinação de tendências, das quais, podemos destacar e contrapor à realidade dos tempos de impactos da Pandemia Covid-19 na educação, tal como:

d) A crítica pós-moderna à ideia que os processos educacionais podem e devem ser controlados por professores: nas notas aqui analisadas, o papel do professor foi ressaltado como primordial em todas as ações propostas para continuidade do processo ensino-aprendizagem;

e) A chamada explosão silenciosa da aprendizagem como evidenciada pelo enorme crescimento da aprendizagem informal na vida das pessoas: As notas apresentam grande preocupação com a aprendizagem realizada pelos estudantes em função dos conteúdos escolares e no contato com os(as) professores(as), inclusive, o Banco Mundial (2020, p.02) deixa claro que: "A ausência de interação entre estudantes e professores rompe o processo de aprendizagem e se a pandemia durar muitas semanas, não será possível recuperar o tempo perdido quando as escolas reabrirem."

Ensaio crítico sobre as possíveis estratégias adotadas para o enfrentamento ao fechamento das escolas provocado pela COVID-19: rede municipal de educação básica de Campinas (SP) - 
Congreso Internacional de Gestión Educativa, 06 y 07 de noviembre de 2020.

Pontificia Universidad Católica del Perú

f) A erosão do Estado do Bem-estar e a subsequente ascensão das políticas de educação neoliberais nas quais o indivíduo é priorizado em relação a outros fatores, o que muda a responsabilidade pela aprendizagem continuada (ao longo da vida) do provedor para o consumidor, transformando a educação de um direito, em um dever: Os dados brasileiros de acesso à internet, de acesso a equipamentos de tecnologia da informação (TICs), de apoio familiar para o estudo em casa, de formação para trabalho com tecnologias educacionais para os professores e de escolas com equipamentos e uso de internet apresentados nas notas analisadas, revelam uma grande desigualdade socioespacial que remete à responsabilidade constitucional do Estado (poder público) na garantia do direito à educação, mesmo em tempos de calamidade pública - Pandemia Covid-19, promovendo todos os meios necessários para o acesso e permanência dos estudantes nas escolas.

\section{Conclusiones}

No Brasil, caso os gestores considerem precipuamente que a educação é o principal motor de crescimento econômico e mobilidade social, a pandemia emperrou esse motor e está tendo um impacto imediato sobre as desigualdades;

A crise gerada pela Covid 19 escancarou a falta de uma governança nacional para a Educação.

\section{Referencias bibliográficas}

AZANHA, J.M.P. Uma ideia de pesquisa educacional. São Paulo: Edusp, 1992.

BANCO MUNDIAL. "Políticas Educacionais na Pandemia da COVID-19: O que o Brasil pode aprender com o resto do mundo?”. Nota técnica, abril/2020. Disponível em: <https://www.worldbank.org/pt/country/brazil/publication/brazil-educationpolicy-covid-19-coronavirus-pandemic>. Acessado em junho de 2020.

BIESTA, G. Boa educação na era da mensuração. Cadernos de Pesquisa, v.42 n.147, p.808-825 set./dez. 2012. Disponível em: https://www.scielo.br/pdf/cp/v42n147/09.pdf. Acessado em junho de 2020.

BRASIL. Decreto 9.057/2017, que Regulamenta o art. 80 da Lei no 9.394, de 20

de dezembro de 1996, que estabelece as diretrizes e bases da educação nacional. Disponível em:

http://www.planalto.gov.br/ccivil_03/_ato2015-2018/2017/decreto/d9057.htm. Acessado em junho de 2020.

Lei de Diretrizes e Bases da Educação Nacional. Lei no 9.394. 1996.

Medida Provisória $n^{\circ}$ 934/2020, que institui Normas excepcionais sobre a duração do ano letivo. Disponível em: https://www.congressonacional.leg.br/materias/medidas-provisorias//mpv/141349. Acessado em junho de 2020. 
Congreso Internacional de Gestión Educativa, 06 y 07 de noviembre de 2020.

Pontificia Universidad Católica del Perú

Ministério da Educação. Conselho Nacional de Educação Conselho Pleno. Parecer CNE/CP $\mathrm{n}^{\circ} \quad 11 / 2020$. Disponível em: http://portal.mec.gov.br/index.php?option=com_docman\&view=download\&alia $\mathrm{s}=148391-$ pcp011-20\&category_slug=julho-2020pdf\&Itemid=30192. Acessado em junho de 2020.

Ministério da Educação. Conselho Nacional de Educação Conselho Pleno. Parecer CNE/CP $\quad \mathrm{n}^{\mathrm{o}}$ 05/2020. Disponível em: http://portal.mec.gov.br/index.php?option=com_docman\&view=download\&alia s=145011-pcp005-20\&category_slug=marco-2020-pdf\&Itemid=30192.

Acessado em junho de 2020.

CAMPINAS. Conselho Municipal de Educação. Resolução CME nº 01/2020, de 16 de abril de 2020. Publicada no DOM em 24 de abril de 2020, p. 02. Disponível em: http://portal.mec.gov.br/seed/arquivos/pdf/tvescola/leis/lein 9394.pdf. Acessado em junho de 2020.

CAMPINAS. Secretaria Municipal de Educação." Princípios orientadores para a atuação dos profissionais do DEPE e CEIs durante o isolamento social devido à Covid-19." Disponível

em: https://sites.google.com/educa.campinas.sp.gov.br/smeteletrabalho/educa\%C3\% A7\%C3\%A3o-infantil/propostas-de-trabalho?authuser=0. Acessado em agosto de $2020 \mathrm{~b}$.

LARROSA, J. Esperando não se sabe o quê: sobre o ofício de professor. Belo Horizonte: Autêntica Editora, 2018.

POPKEWITZ, T. e LINDBLAD, SVERKER. A fundamentação estatística, o governo da educação e a inclusão e exclusão sociais. Ed. Soc. Campinas, v. 37, $n^{\circ} 136$, p.727-754, jul.-set., 2016.

TODOS PELA EDUCAÇÃO. "Análise: ensino a distância na educação básica frente à Pandemia da Covid-19". Nota técnica, abril/2020. Disponível em: https://www.todospelaeducacao.org.br/_uploads/_posts/425.pdf. Acessado em junho de 2020.Texto de la ponencia.

Ensaio crítico sobre as possíveis estratégias adotadas para o enfrentamento ao fechamento das escolas provocado pela COVID-19: rede municipal de educação básica de Campinas (SP) Brasil - Vitorino, Artur \& Mello, Juliano.

DOI: https://doi.org/10.18800/cige2020.007 